Quebec Cooperative Study of Friedreich's Ataxia

\title{
A Preliminary Study of Dynamic Muscle Function in Hereditary Ataxia
}

\author{
C. RICHARDS, J.P. BOUCHARD, R. BOUCHARD and H. BARBEAU
}

SUMMARY: Dynamic muscle function was evaluated in nine patients with Friedreich's ataxia $(F A)$ and eight with autosomal recessive spastic ataxia of Charlevoix-Saguenay (ARSACS). The measurement of torque throughout maximum voluntary isokinetic knee movements was used to quantitatively describe muscle weakness in the ataxic patients. Both FA and ARSACS patients were shown to have decreased dynamic strength in comparison to normal values during knee extension and flexion movements at $30^{\circ} \mathrm{s}$. In the FA patients a lower torqueproducing capacity was seen in the older patients.

The electromyographic (EMG) activity was recorded in lower extremity muscles during the movements. In the vastus

RÉSUMÉ: Une évaluation de la dynamique musculaire fonctionnelle a été réalisée auprès de 17 patients dont 9 présentaient de l'Ataxie de Friedreich (FA) et 8 de l'ataxie spastique familiale de Charlevoix-Saguenay (ARSACS). La description de la faiblesse musculaire des ataxiques a été effectuée par le biais de l'évaluation du torque au cours de mouvements volontaires isokinétiques au niveau du genou. Au cours des mouvements de flexion et d'extension du genou à $30^{\circ} / s$, dans les deux groups d'ataxiques ( $F A$ et $A R S A C S)$ une diminution de la force dynamique a été observée comparativement aux valeurs normales. Dans le groupe de patients $F A$, cette diminution de force s'est avérée plus importante chez les patients plus âgés.

L'activité électromyographique (EMG) de cinq muscles du membre inférieur a été enregistrée au cours des mouvements du

\footnotetext{
From the Centre de Recherche en Neurobiologie, Ecole de Réadaptation, Université Laval, and Département des Sciences Neurologiques, Hôpital de l'EnfantJésus, 1401, 18e Rue, Québec.

Reprint requests for the complete supplement on Friedreich's Ataxia (phase three) to: Dr. André Barbeau, Clinical Research Institute of Montreal, 110 Pine Avenue West, Montreal, Quebec, H2W IR7. Canada.
}

lateralis (VL), deviations from the normal EMG activation pattern were described in both groups of patients. A reduced amplitude in the EMG activity in the medial hamstrings $(M H)$ was seen in the majority of the patients. An index of coactivation was defined by comparing the EMG activity when a muscle lengthened (antagonistic) to the EMG activity when the same muscle shortened (agonistic) during the isokinetic contractions. In comparison to normal values increased coactivation indexes were present in the $V L$ and $M H$ in patients of both groups. The characteristics of dynamic muscle strength and the activation of agonistic and antagonistic muscles described in the present study will provide the basis of evaluation for the effects of therapy in these patients.

genou. Dans le vaste externe (VL), les déviations dans les patrons d'activité (EMG) par rapport aux valeurs normales ont été décrites pour les deux groupes de patients. Dans la majorité des cas, l'amplilude de l'activité EMG dans l'ischiojambier interne (MH) était réduite. Un index de co-activation a été défini en comparant l'activité EMG du muscle allongé (antagoniste) à l'activité EMG du même muscle lorsque raccourci (agoniste) au cours de contractions isokinétiques. Pour les deux groupes de patients, les index de co-activation, par rapport aux valeurs normales, se sont avérés plus élevés, tant dans le VL que dans le MH. Les caractéristiques relatives à la force musculaire dynamique, et l'activité des muscles agonistes et antagonistes telles que décrites dans la présente étude seront utilisées ultérieurement pour évaluer les effets thérapeutiques chez ces mêmes patients.

\section{INTRODUCTION}

Since Friedreich reported his clinical observations between 1863 and 1877 , the neuromuscular dysfunction in the heredo-familial ataxia named after him has been known to include ataxia, sensory loss and decreased proximal muscle power in the later stages (Tyrer, 1975; Andermann, 1976). According to Tyrer (1975) "Friedreich described the ataxia in great detail, stressing the effects on gait, the involvement on all four limbs and the aggravation of the ataxia by voluntary movement . . Motor weakness of varying degree, usually first in the lower limbs and later in the upper, was present in all cases, sometimes in advanced stages almost amounting to paralysis ... In early cases Friedreich stated that no muscle wasting was present; however, late in the disease, he described significant muscle wasting."

Several authors (Bell and Carmichael, 1939; Wilson, 1954; Brown, 1962) have suggested a greater motor weakness in the lower extremities which is progressive. Brown (1962) found the flexor muscles to frequently be more affected than the extensor muscles and Grinker and Sahs (1966) described distal muscles to be more affected than proximal muscles. This weakness may progress to paralysis (Spiller, 1910).

Friedreich's ataxia (FA) is the most common variety of the heredo-ataxias (Pratt, 1967). In a comprehensive clinical study, Geoffroy et al., (1976) have described a constellation of signs constantly present in typical cases of FA submitted to the protocol of the Quebec Cooperative Study on Friedreich's Ataxia. In the 36 typical cases studied, muscle weakness with or without hypotonia was noted to be present in $100 \%$ of the patients. 
Recently, Bouchard et al., (1978) described a new syndrome of autosomal recessive spastic ataxia of Charlevoix-Saguenay (ARSACS) isolated in this region of Quebec. The neuromuscular dysfunction in these patients was characterized by spasticity, distal muscle wasting and weakness, pes cavus and gait ataxia.

Generally, these descriptions of muscle weakness have not specified the method of strength evaluation and have included statements such as "slight to gross motor weakness" (Tyrer and Sutherland, 1961), or the presence or absence of muscle weakness as determined by "clinical" evaluations. Although muscle weakness has been included as a cardinal symptom in FA and to a lesser degree in ARSACS, to our knowledge quantitative studies of muscle strength in heredo-ataxic patients have not been described. Quantitative evaluations of functional muscle control during standardized motor tasks in heredo-ataxic patients have not been described despite the marked motor control disturbances observed in clinical evaluations.

The suggested beneficial effects on muscle strength of lecithin administered to FA patients (Barbeau, 1978) gave the impetus to a more extensive study of the effects of this drug on functional motor control in heredoataxic patients. To provide a basis for the evaluation of the effects of the lecithin therapy, a detailed study of dynamic function in the knee extensor and flexor muscles was initiated in a group of 17 heredo-ataxic patients (FA and ARSACS). Dynamic strength and muscle activation patterns in five lower extremity muscles were studied during isokinetic knee movements at three angular velocities in all the patients before the therapy was initiated. The drug trial is presently in progress.

The purposes of this paper are: 1) to describe a quantitative method of evaluation for dynamic muscle function in ataxic patients and 2) to apply this method to the description of some characteristics of dynamic muscle function in two groups of heredoataxic patients. These data will provide the basis for future descriptions of the effects of therapy on dynamic muscle function, measured by the same method, in these patients.

\section{SUBJECTS AND METHODS}

\section{$I-a)$ Patients}

Dynamic muscle function was evaluated in 17 heredo-ataxic patients. According to clinical and electrophysiological criteria previously described (Bouchard et al, 1978; Bouchard et al., 1979a) the patients were divided into two groups. The first group consisted of 9 patients with Friedreich's ataxia (FA) and the second group 8 patients with autosomal recessive spastic ataxia of Charlevoix-Saguenay (ARSACS). The FA group was composed of 3 female and 6 male patients with an average age of 20 yrs. Five of these patients were confined to wheelchairs, and four could walk unassisted. The average age of the ARSACS group was $30 \mathrm{yrs}$ and consisted of 4 women and 4 men. Three of these patients could walk unassisted and the remaining 5 required assistance.

Clinical findings which characterize the FA and ARSACS patient groups have been described in detail (Geoffroy et al., 1976; Bouchard et al., 1978; Bouchard et al., 1979a). Recent electrophysiological studies (Bouchard et al., 1979b) have also outlined differences in the neuromuscular function in these two groups. Table I gives a summary of some clinical findings related to trunk and lower extremity function in the patients included in the present study.

\section{b) Healthy subjects}

The characteristics of dynamic muscle function in the patients were described in comparison to normal data derived with similar method of evaluation in healthy women, most of them working in the field of rehabilitation (Richards, 1980). For the torque data, the mean age was $38.4 \pm 11.7$ years (mean, \pm 1 S.D.) $(\mathrm{N}=19)$ with a range of $21-60$ years; and the weight $59.3 \pm 8.3 \mathrm{kgs}$ with a range of 49.5 $75.0 \mathrm{kgs}$. The electromyographic data was taken from 17 healthy women, age: $38.2 \pm 12.3$ years (mean, \pm 1 S.D.) with a range of $21-60$ years and weight: $60.1 \pm 8.4 \mathrm{kgs}$; range $49.5-75.0$ kgs. Strength measurements during isokinetic knee movements in healthy men $(N=79)$ were described by Knutsson and Mårtensson (1976).

\section{II - a) Dynamic Muscle Strength}

Maximal voluntary isokinetic contraction strength in the knee extensor and flexor muscles was measured with the

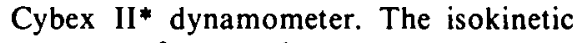
concept of strength measurement was introduced in 1967 (Hislop and Perrine, 1967; Thistle et al., 1967). In the last decade, the isokinetic principle has been applied to the evaluation of dynamic muscle strength in healthy subjects (Thorstensson, 1976; Larsson et al., 1979; Coyle et al., 1979) and in patients with musculoskeletal (Nicholas et al., 1976; Campbell and Glenn, 1979; Richards, 1980) or neurological disorders (Knutsson and Mårtensson, 1976). The main components of the isokinetic dynamometer are: the dynamometer clock, speed control unit and devices for monitoring torque and angular displacement. Torque is a force which acts about an axis of rotation (force $\mathrm{x}$ its perpendicular distance from the axis of rotation). The metric unit of torque is the Newton-meter $(\mathrm{Nm})$.

The dynamometer controls the speed of movement by preventing the speed from rising above a preset level and the output of momental force at that speed is measured. A force must be applied against the dynamometer arm to move it. When the preset speed of the dynamometer arm has been reached, a braking mechanism which prevents the dynamometer arm from rotating at a faster speed is activated. The resistance given to the movement is equal to the force applied whether it is large or small. Movements below the preset speed are not resisted nor is the output of momental force measured.

Joint motion was tracked by a uniaxial electrogoniometer which measured displacements of the machine lever arm to which the lower leg was attached. Torque was recorded as pressure changes within the dynamometer by a pressure sensitive potentiometer. The torque and angle signals were amplified and recorded with the $x-y$ display feature of a Tektronix storage oscilloscope and simultaneously against time on the inkwriter of a Grass polygraph. Electronic calibration signals for the torque and angle measurements were checked by dropping weights at a fixed distance from the axis of rotation and by manually measuring the knee angle.

The reliability and validity of the Cybex II isokinetic dynamometer has been

*Cybex II, Manufactured by Lumex Inc., Bay Shore, New York. N.Y. 
TABLE I

Friedreich's Ataxia

\begin{tabular}{|c|c|c|c|c|c|c|c|c|}
\hline Patient & Age & Sex & $\begin{array}{c}\text { Age of } \\
\text { onset }\end{array}$ & Gait & $\begin{array}{l}\text { Deep tendon } \\
\text { reflexes }\end{array}$ & Scoliosis & $\begin{array}{l}\text { Babinski } \\
\text { bilateral }\end{array}$ & Pes cavus \\
\hline $\mathrm{SG}$ & 11 & $\mathbf{M}$ & $4-6$ & 4 & A & A & $\mathbf{P}$ & $\mathbf{P}$ \\
\hline $\mathbf{P M}$ & 14 & $\mathbf{M}$ & 13 & 4 & A & $\mathbf{P}$ & no response & $\mathbf{P}$ \\
\hline $\mathrm{MG}$ & 16 & $\mathrm{~F}$ & $9-10$ & 3 & $\mathbf{A}$ & $\mathbf{P}$ & $\mathrm{P}$ & A \\
\hline $\mathrm{CG}$ & 19 & $\mathbf{M}$ & 13 & 3 & A & $\mathbf{P}$ & $\mathbf{P}$ & $\mathbf{P}$ \\
\hline NT & 20 & $\mathbf{M}$ & $8-12$ & 0 & A & $\mathbf{P}$ & $\mathbf{P}$ & $\mathbf{P}$ \\
\hline ML & 23 & $\mathrm{~F}$ & 7 & 0 & A & $\mathbf{P}$ & $\mathbf{P}$ & $\mathbf{A}$ \\
\hline DJ & 23 & $\mathbf{M}$ & 7 & 0 & A & $\mathbf{P}$ & $\mathbf{P}$ & $\mathbf{P}$ \\
\hline PB & 26 & $\mathbf{M}$ & 5 & 0 & A & $\mathbf{P}$ & $\mathbf{P}$ & $\mathbf{P}$ \\
\hline $\mathrm{MG}$ & 27 & $\mathrm{~F}$ & 13 & 0 & A & $\mathbf{P}$ & $\mathrm{P}$ & $\mathbf{P}$ \\
\hline
\end{tabular}

Autosomal Recessive Spastic Ataxia Charlevoix-Saguenay

\begin{tabular}{|c|c|c|c|c|c|c|c|c|}
\hline LG & 23 & $F$ & $*$ & 3 & B & A & $\mathbf{P}$ & $P$ \\
\hline$F J$ & 25 & $\mathbf{M}$ & $*$ & 3 & B & A & $\mathbf{P}$ & $\mathbf{P}$ \\
\hline JT & 27 & $\mathrm{~F}$ & $*$ & 3 & B & A & $\mathbf{P}$ & $\mathbf{P}$ \\
\hline $\mathrm{CG}$ & 31 & $\mathbf{M}$ & $*$ & 1 & B & A & $\mathbf{P}$ & $\mathrm{P}$ \\
\hline $\mathrm{JMG}$ & 32 & $\mathbf{M}$ & $*$ & 1 & $B$ & A & $\mathbf{P}$ & $\mathrm{P}$ \\
\hline $\mathrm{CS}$ & 33 & $F$ & $*$ & 1 & $\mathbf{N}$ & A & $\mathbf{P}$ & $\mathbf{P}$ \\
\hline $\mathrm{GD}$ & 36 & $\mathrm{~F}$ & * & 2 & B & A & $\mathbf{P}$ & A \\
\hline CF & 41 & $\mathbf{M}$ & * & 1 & A & A & $\mathbf{P}$ & $\mathrm{P}$ \\
\hline
\end{tabular}

LEGEND:

$\begin{array}{ll}\text { F: FEMALE } & \text { A: ABSENT } \\ \text { M: MALE } & \text { P: PRESENT } \\ & \text { B: BRISK } \\ & \text { N: NORMAL }\end{array}$

*Evidence of onset with delayed or abnormal gait development
Ambulatory status was described on a scale $(0-5)$ :

$$
\begin{aligned}
& 5 \text { - Normal gait } \\
& 4 \text { - Minimal ataxic gait } \\
& 3 \text { - Staggering gait (independent) } \\
& 2 \text { - Staggering gait (with assistance) } \\
& 1 \text { - Wheelchair (supported gait) } \\
& 0 \text { - Wheelchair (unable to walk) }
\end{aligned}
$$

reported by Moffroid et al., (1969). In the present study, the frequency response of the torque measuring system was about 90 $\mathrm{Hz}$ when using the oscilloscope and a specially designed amplifier. When the torque was recorded against time on the inkwriter, the frequency response was reduced to about $25 \mathrm{~Hz}$.

\section{b) The Recording of Electromyograms}

Electromyograms were taken with surface electrodes fixed to the skin over five muscles of the lower extremity. The skin was cleansed with alcohol and the electrodes were placed about $5 \mathrm{~cm}$ apart in specific locations on the vastus medialis (VM), vastus lateralis (VL), medial hamstrings ( $\mathrm{MH}$ ), lateral gastrocnemius (LG), and tibialis anterior (TA) muscles. Each Beckman $16 \mathrm{~mm}$ electrode was held in place by a tape collar which sealed the contact jelly in a chamber between the contact surface of the electrode and the skin. The electrode leads were raised and held $0.5-1 \mathrm{~cm}$ above the skin surface by surgical tape attachments to reduce movement artifacts in the recordings to an acceptable level (Knutsson and Richards, 1979).
The myosignals were fed to a.c. preamplifiers and recorded on a Grass polygraph (type 7D) first as unintegrated (raw) EMG to check for movement artifacts and subsequently the EMG signals were rectified and time averaged by a resistor-capacitor ( $R C$ ) integrator in the preamplifiers (Grass, type 7P3b). For analysis purposes the "integrated" EMG (IEMG) with a time constant of $0.2 \mathrm{~s}$ was chosen to estimate the EMG activity. Although this relatively long time constant limited estimation of the timing of the EMG activity, it permitted an estimation of the average $E M G$ activity and introduced a delay in the recordings that corresponded roughly to the delay between muscle action potentials and the contractions they elicit (Knutsson and Richards, 1979). The IEMG was calibrated with an internal 500 $\mathrm{Hz}$ square wave provided with the same voltages as the preamplifier and accurate to $\pm 3.0 \%$

\section{c) Experimental Protocol}

Subjects were seated on a specially designed table with a back support and the hip angle flexed approximately $100^{\circ}$. Straps were placed across the shoulders, hips and thigh for stabilization, and subjects were requested to grip the sides of the table with both hands and maintain a stable body position. The dynamometer rotational axis was aligned to the estimated center of rotation of the knee joint and the lever arm was attached to the lower leg by means of a padded interface.

To standardize the head position, subjects were asked to observe the stored $\mathrm{x}$ $y$ display of their torque-angle curves on the oscilloscope placed in front of them. To brisk commands, kept constant throughout the study, the subjects performed knee extension and flexion movements through a $90^{\circ}$ arc from a flexed position to a fully extended position or vice versa. They were instructed to push against the dynamometer arm as "hard" and as "fast" as possible. The subject performed the movement in one direction and the lower leg was returned to the starting position by the experimenter. For flexion movements, the knee joint was passively extended and held in position by the experimenter.

The speed selector was set at 30,90 and 180 degrees per second $(\% / \mathrm{s})$. Three repetitions at each speed for first extension and then flexion movements were recorded and 
EXTENSION
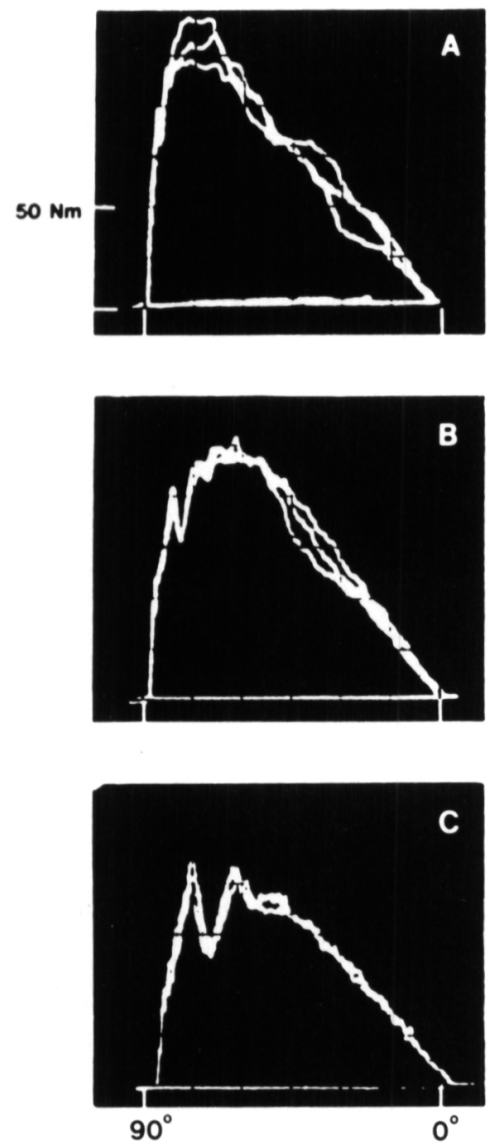

FLEXION
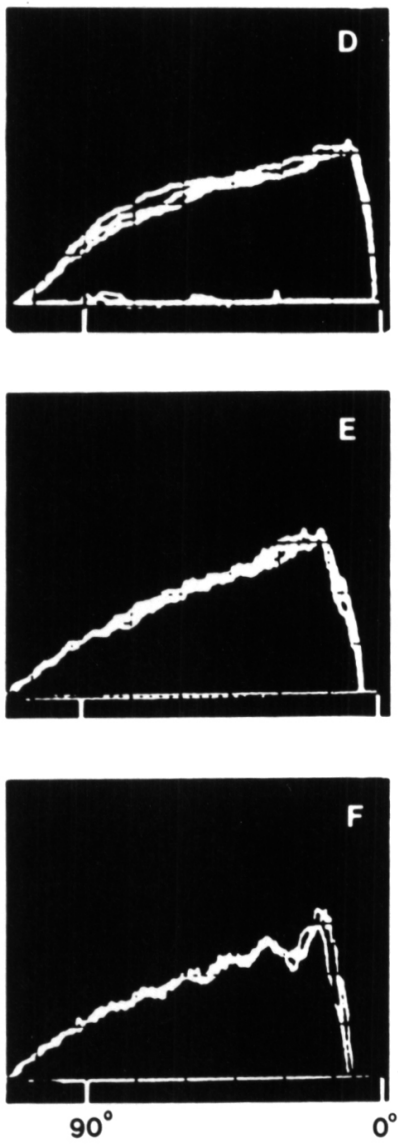

$90 \%$

$180 \%$

KNEE ANGULAR POSITION IN DEGREES

Figure 1 - Torque records photographed from the X-Y display of a storage oscilloscope during isokinetic knee movements in a healthy woman. In A-C, extensor torque is recorded on the $\mathrm{Y}$-axis as the knee moves from $90^{\circ}$ to $0^{\circ}$ (X-axis). Flexor torque (D-F) is recorded as the knee moves from $0^{\circ}$ to $90^{\circ}$. Each record (A-F) represents three repetitions of the isokinetic movements at $30^{\circ} / \mathrm{s}, 90^{\circ} / \mathrm{s}$ and $180^{\circ} / \mathrm{s}$.

stored on the oscilloscope and simultaneously on the Grass Polygraph. A Polaroid photograph was taken of the three repeated torque-angle curves on the oscilloscope. Figure I illustrates a series of torque-angle curves recorded in a normal subject. Since each photograph (A-F) represents three contractions, a total of 18 contractions were recorded at different angular velocities for extension and flexion movements. These torque-angle curves reflect the capacity of the subject to produce muscular force throughout the range of movement at pre-determined constant angular velocities. The increased latency in the beginning of the torque recordings at $180^{\circ} / \mathrm{s}$ in comparison to $30^{\circ} / \mathrm{s}$ is related to the time needed for the subject to attain the faster angular velocity. When the predetermined velocity is attained the dynamometer suddenly resists the accelerating lower leg causing an initial overshoot in the torque tracings. This initial overshoot is particularly noticeable in the torque-angle curves recorded at $180^{\circ} / \mathrm{s}$ when the torque-producing capacity is reduced.

The gravitational torque due to the weight of the lower leg and the recording lever arm was measured by allowing the lower leg to fall from full extension at a very low angular velocity. Correction was made for this torque in the calculation of knee extensor and flexor torque throughout the movement.

The electromyograms from the respective muscles were recorded simultaneously to the torque and angle data during the isokinetic knee movements. Figure 2 illustrates the torque, angle and EMG recordings during three repetitions of knee extension at $30^{\circ} / \mathrm{s}$ in a healthy woman. In $A$, the raw $E M G$ is recorded to check for abnormal potentials due to artifacts. In B and $C$ the EMG signals are modified by the integrator circuit with a time constant of $0.02 \mathrm{~s}$ and 0.2 respectively.

\section{RESULTS}

\section{Friedreich's Ataxia (FA)}

Figure 3 gives a series of torqueangle curves photographed from the oscilloscope tracings in a 20 year old male FA patient. A lack of reproducibility in the shape and amplitude of the three torque-angle curves is seen during the knee extension (A) and flexion (B) movements at $30^{\circ} / \mathrm{s}$. Other deviations which can be observed include: decreased angular motion, a rapid decay in torque amplitude as the knee joint is extended (A) and lower peak torque in comparison to the torque-angle curves in Figure 1. Generally, the FA patients demonstrated more variability in the three repeated torque-and-angle curves for the isokinetic extension and flexion movements in comparison to healthy subjects, particularly at $30^{\circ} / \mathrm{s}$.

The capacity to produce torque varied greatly among the patients and was related to the ambulatory status in the individual patients. The shape and amplitude of the series of torque-angle curves in the young patients who could walk unassisted were similar to normal. In contrast, the torque-angle characteristics in the wheelchair-bound patients deviated markedly from values in normal subjects (Richards, in press a). To illustrate the evolution of changes in the dynamic strength capacity with progression of the disease, the torque-angle curves measured in two sisters are given in comparison to normal values in Figure 4. At the time of evaluation, the younger sister (MG 16) was 16 years old and walked unassisted (grade 3), the older sister (MG 27) was 27 years old and had been in a wheelchair for about 10 years. It can be seen from the figure that the amplitude of the extension torque-angle curves in the younger sister (interrupted lines) are decreased relative to normal values, however the flexion torque-angle curves are similar to normal values. In the older sister (open circles) the amplitude and angular excursion of the torque-angle curves during extension movements deviate markedly from normal values. An even greater 
loss in capacity to produce torque at the predetermined angular velocities is demonstrated in the knee flexion curves.

To further describe the muscle function in individual FA patients, the torque-angle and muscle activation characteristics in an agonistic muscle during isokinetic movements at $30^{\circ} / \mathrm{s}$ are given for the 9 patients in comparison to normal values in Figure 5. The series of torque-angle tracings ( $A$ and $C$ ) demonstrate the decreased ability to produce high torque values in both the female (thin lines) and male (interrupted lines) patients. In addition, a lack of full active knee extension can be observed in some patients in $A$ and a lack of passive (held by experimenter) knee extension in $\mathrm{C}$. In $\mathrm{A}$, extension torque measurements in the patients are given for each $9^{\circ}$ of knee movement corresponding to recorded torque. Note also the decreased ability of the patients to produce torque in the early part of the extension (A) and flexion (C) movements and the marked variability among the subjects. In $\mathrm{C}$, two women patients were unable to produce flexion torque and the knee flexion movements in these two patients are superimposed (small open circles). For clarity large and small squares illustrate the torque-angle curves in two men.

In $B$ and $D$, the EMG activity pattern in the vastus lateralis (VL) and medial hamstrings $(\mathrm{MH})$ in the individual FA patients are given in comparison to normal values. In $B$, it is possible to visualize the timing and amplitude of the VL as the knee moves from $90^{\circ}$ of knee flexion to full extension. For the $\mathrm{MH}$ in $\mathrm{D}$, the movement begins in full extension.

The torque $(A, C)$ and EMG $(B, D)$ information roughly describes the interaction between the muscle activation and torque produced in the individual subjects. The timing and amplitude of the EMG activity patterns in both VL and $\mathrm{MH}$ deviate from the normal to various degrees in the individual patients. The amplitude of the $\mathrm{MH}$ activity was generally reduced relative to the mean normal activation level in all the patients. In both the VL (B) and $\mathrm{MH}$ (D) EMG activity was present before the beginning of the
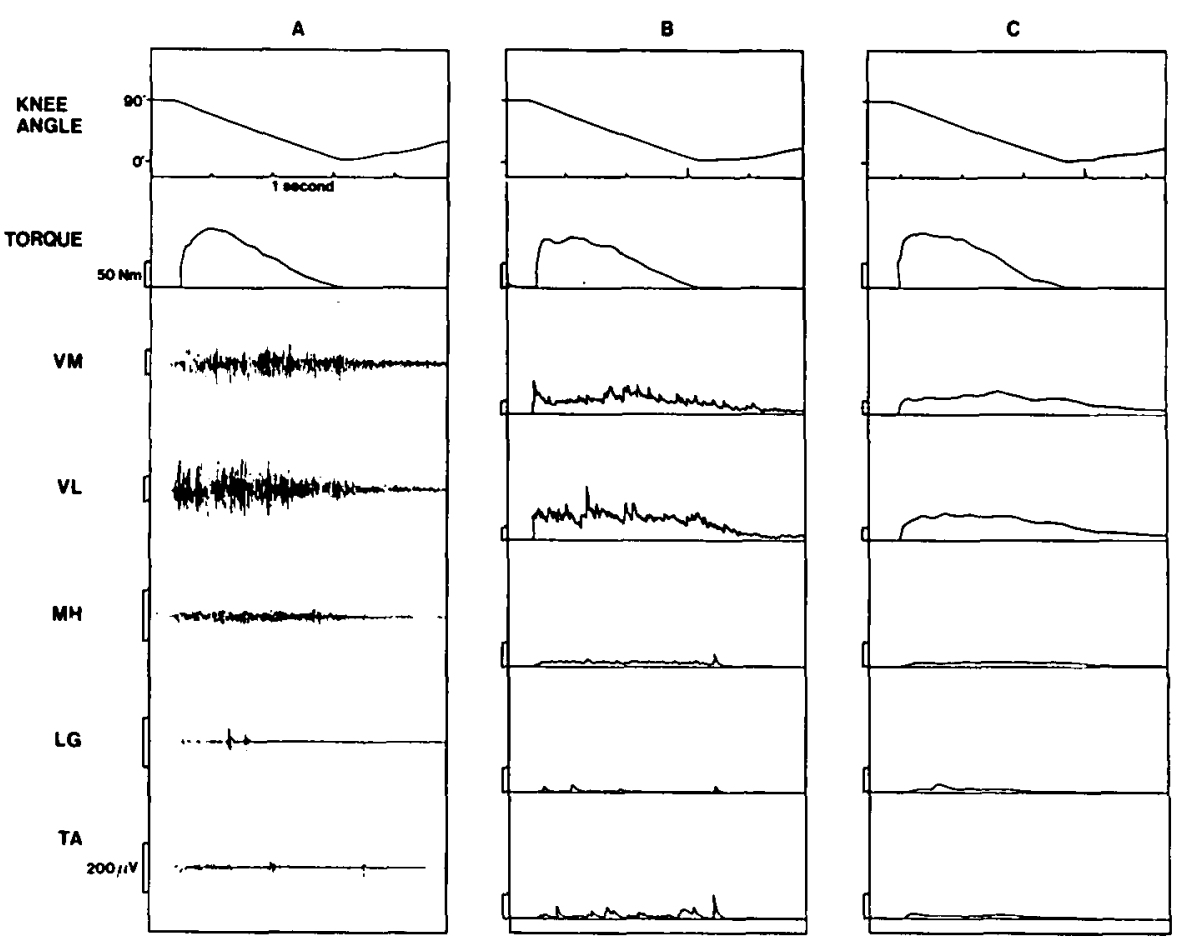

Figure 2 - Records of the concomitant knee angle, torque EMG data during knee extension at $30^{\circ} / \mathrm{s}$ in a healthy subject. The traces indicate from above: knee angle, torque and the EMG in vastus medialis (VM), vastus lateralis (VL), medial hamstrings $(\mathrm{MH})$, lateral gastrocnemius (LG) and, tibialis anterior (TA). Three repetitions of the movement from $90^{\circ}$ to $0^{\circ}$ of knee flexion are recorded in $\mathrm{A}, \mathrm{B}$ and $\mathrm{C}$. In $\mathrm{A}$ the raw EMG is recorded, in $B$ and $C$ the integrated $E M G$ is recorded (time constants of $0.02 \mathrm{~s}$ and 0.2 s). Calibration bar for torque equal to $50 \mathrm{Nm}$ and EMG $200 \mathrm{uV}$.

\section{EXTENSION}

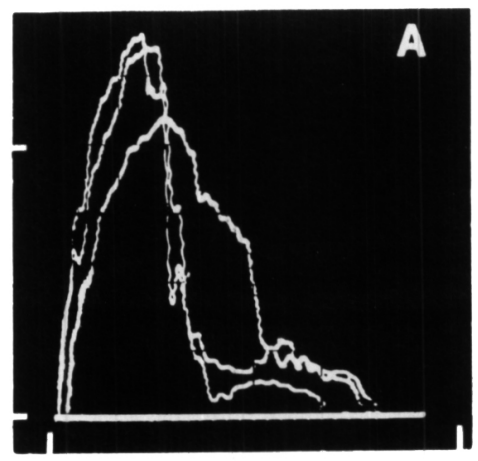

$90^{\circ}$

\section{FLEXION}

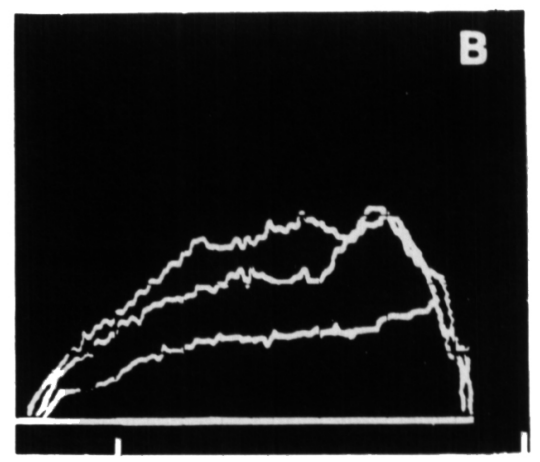

\section{KNEE ANGLE (DEGREES)}

Figure 3 - Torque-angle records photographed from the oscilloscope tracings in a patient with Friedreich's ataxia (NT). Three repeated maximal voluntary isokinetic knee extension (A) and flexion (B) movements at $30^{\circ} / \mathrm{s}$ are superimposed. Torque is given on $\mathrm{Y}$ axis and knee angle on $\mathrm{X}$ axis. Calibration marker in $\mathrm{A}$ indicates $50 \mathrm{Nm}$. 

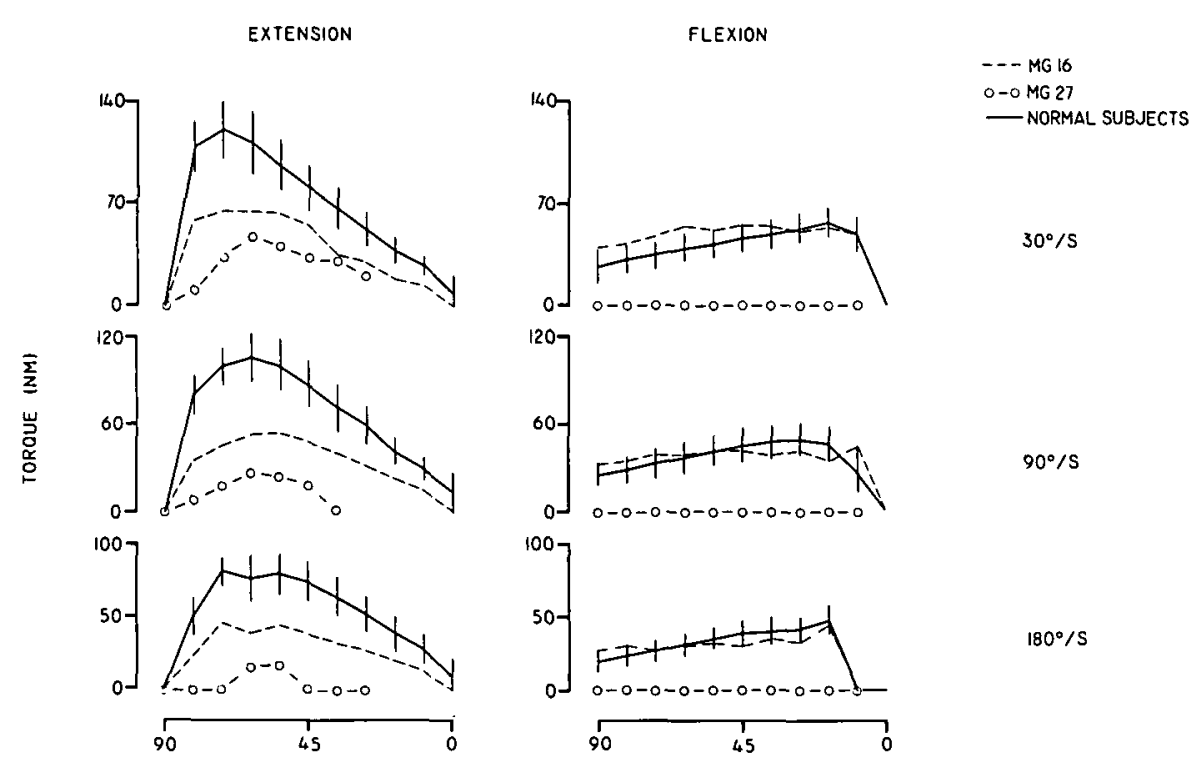

KNEE ANGLE IDEGREESI

Figure 4 - Torque-angle measurements during isokinetic knee movements at $30^{\circ} / \mathrm{s}, 90^{\circ} / \mathrm{s}$ and $180^{\circ} / \mathrm{s}$ in two ataxic patients, MG 16 (interrupted line) and MG 27 (open circles) in comparison to mean values. Solid lines give mean derived from torque measurements $(\mathrm{Nm})$ at each $9^{\circ}$ interval in 19 healthy women and vertical bars indicate $\pm 1 S D$. Patient curves give amplitude of torque relative to normal average peak torque for each movement.

knee movement which determined the first EMG measurement.

The externally measured torque produced by the subjects during the extension and flexion movements was related to the contraction force, restraint due to activation of antagonistic muscles and specifications of the measurement system. A method of estimating antagonistic muscle activation (co-activation) is the monitoring of the EMG activity in the antagonistic muscles during movements. In this study, the term coactivation was applied to the EMG activity in a muscle as it lengthened during maximal voluntary isokinetic movements. Richards (in press b) described a co-activation index during isokinetic knee movements in healthy women: (peak amplitude IEMG isokinetic lengthening/peak amplitude IEMG during isokinetic shortening).

This co-activation index was calculated in the FA patients and compared to normal values. The co-activation index in VL was 3.7 to 7.1 times greater than the index described in normal subjects (11.4 $\pm 5.1 \mathrm{SD}, \mathrm{N}=17)$ in 4 patients (MG 27, ML, DJ and PB) during knee flexion movements at $30^{\circ} / \mathrm{s}$. These 4 patients were wheelchair-bound and 2 were unable to produce flexion torque values at $30^{\circ} / \mathrm{s}$. The co-activation index in VL ranged from $7 \%$ to $12 \%$ in the remaining subjects.

Similar calculations were made for the $\mathrm{MH}$ co-activation during knee extension movements at $30^{\circ} / \mathrm{s}$. The co-activation index in $\mathrm{MH}$ was $11 \%$ or greater in all the $\mathrm{FA}$ patients (normal = $7.5 \% \pm 4.7 \mathrm{SD}, \mathrm{N}=15$ ). The highest coactivation indexes in $\mathrm{MH}(58 \%$ to $100 \%$ ) occurred in the more severely affected patients (MG 27, ML, DJ, and $P B$ ). These high co-activation indexes were related to weak extension torque values in these patients ( 7.4 to $54.0 \mathrm{Nm}$ )

\section{Autosomal Recessive Spastic Ataxia of Charlevoix-Saguenay (ARSACS)}

Figure 6 gives the individual torqueangle measurements ( $A$ and $C$ ) and muscle activation patterns in the VL (B) and MH (D) in the 8 ARSACS patients during isokinetic knee extension and flexion movements at $30^{\circ} / \mathrm{s}$.
The method of graphical representation is similar to that described for Figure 5.

During the knee extension movements, the amplitude of the torque curve (A) in all the women patients (thin, solid lines) was reduced relative the mean normal curve (Richards, in press a) in the first $45^{\circ}$ of knee movement. Two men (interrupted lines) produced peak torque superior to the normal healthy women. However, the levels attained by these patients, 155 $\mathrm{Nm}$ and $171 \mathrm{Nm}$ respectively, remained much lower than the peak torque values of $243 \pm 43 \mathrm{Nm}$ (mean, $\mathrm{SD}, \mathrm{N}=79$ ) reported by Knutsson and Mårtensson (1976) for healthy Swedish men. Five of the patients produced peak extensor torque later in the movement in comparison to the $72^{\circ}$ angle in the normal subjects.

In $B$, the series of EMG activity curves in VL during the knee extension movement illustrate a reduced capacity to activate the VL in some patients, while others activated the muscle to normal amplitude levels (Richards, in press b). In some cases there was an increased resting activity demonstrated by the amplitude of the EMG activity at the $90^{\circ}$ angular position. In 7 patients the peak activity level in the EMG curve was delayed in comparison to the peak in the average normal curve.

During knee flexion movements at $30^{\circ} / \mathrm{s}$, the amplitude of the torque produced (C) was greater than mean normal values in some parts of the knee movement in 3 male patients. The peak flexion torque values in these patients approached values reported by Knutsson and Mårtensson (1976) for healthy males. The amplitude of the torque-angle curve was reduced throughout the movement relative to the normal values in all the women patients (thin lines) and in one of the male patients (interrupted lines). The most obvious finding in the comparison of the MH activation patterns in D is the marked general decrease in the amplitude of EMG activity throughout the movement in the majority of the patients. Abnormalities in the timing of the activation can also be described among the patients.

The co-activation index for $\mathrm{VL}$ during knee flexion at $30^{\circ} / \mathrm{s}$ was 2.4 to 
5.1 times greater than the mean normal $(11.4 \%)$ in 3 patients (GD, LG and $\mathrm{CF}$. In the remaining 5 patients the index varied from $11 \%$ to $14 \%$. In the MH during knee extension movements at $30^{\circ} / \mathrm{s}$, the co-activation index was $13 \%$ to $40 \%$ in 5 patients (normal = $7.5 \% \pm 4.7$ S.D. $\mathrm{N}=15$ ) and from $8 \%$ to $12 \%$ in the remaining 3 patients $(\mathrm{CG}$, FJ, CF).

In two male patients, a clonic discharge of EMG activity in the knee extensor muscles was elicited during isokinetic knee flexion movements. Figure 7 gives the polygraph tracings of knee angle, torque and EMG activity in the VM, VL and $\mathrm{MH}$ in A and $\mathrm{B}$ during knee flexion at $30^{\circ} / \mathrm{s}$. Note the bursts of EMG activity in the VM and VL muscles which are antagonists to the movement. This clonic discharge had a frequency of about 7 $8 / \mathrm{s}$ and could be visually observed as a patellar clonus. In this patient the clonus occurred during flexion movements at $30^{\circ} / \mathrm{s}, 90^{\circ} / \mathrm{s}$ and $180^{\circ} / \mathrm{s}$. In the second patient the clonic discharges were not observed at $30^{\circ} / \mathrm{s}$ but were elicited during flexion movements at $90^{\circ} / \mathrm{s}$ and $180^{\circ} / \mathrm{s}$.

\section{DISCUSSION}

\section{Dynamic Muscle Strength}

In this study, dynamic muscle strength was evaluated in two groups of heredo-ataxic patients by quantitative methods. Dynamic strength was defined from measurements of torqueangle curves recorded during isokinetic knee extension and flexion movements at three angular velocities. The measurement of dynamic muscle strength at a constant velocity of muscle shortening is well known to muscle physiologists. However, it was not until the introduction of a commercially available isokinetic dynamometer applicable to the measurement of dynamic strength in human subjects, that isokinetic strength measurements became more widespread (Hislop and Perrine, 1967; Thistle et al., 1967).

The isokinetic dynamometer has been used by several groups of investigators to evaluate dynamic muscle strength. Characteristics of dynamic muscle strength in healthy young men and women (Thorstensson et al., 1976; Knutsson and Mårtensson, 1976;

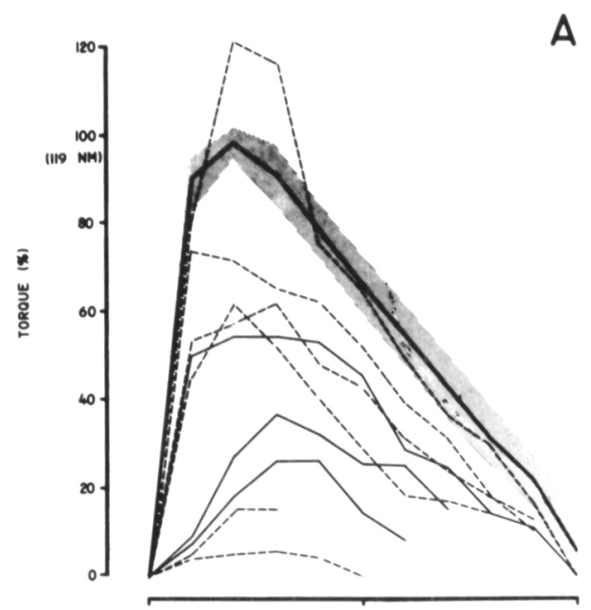

A

C
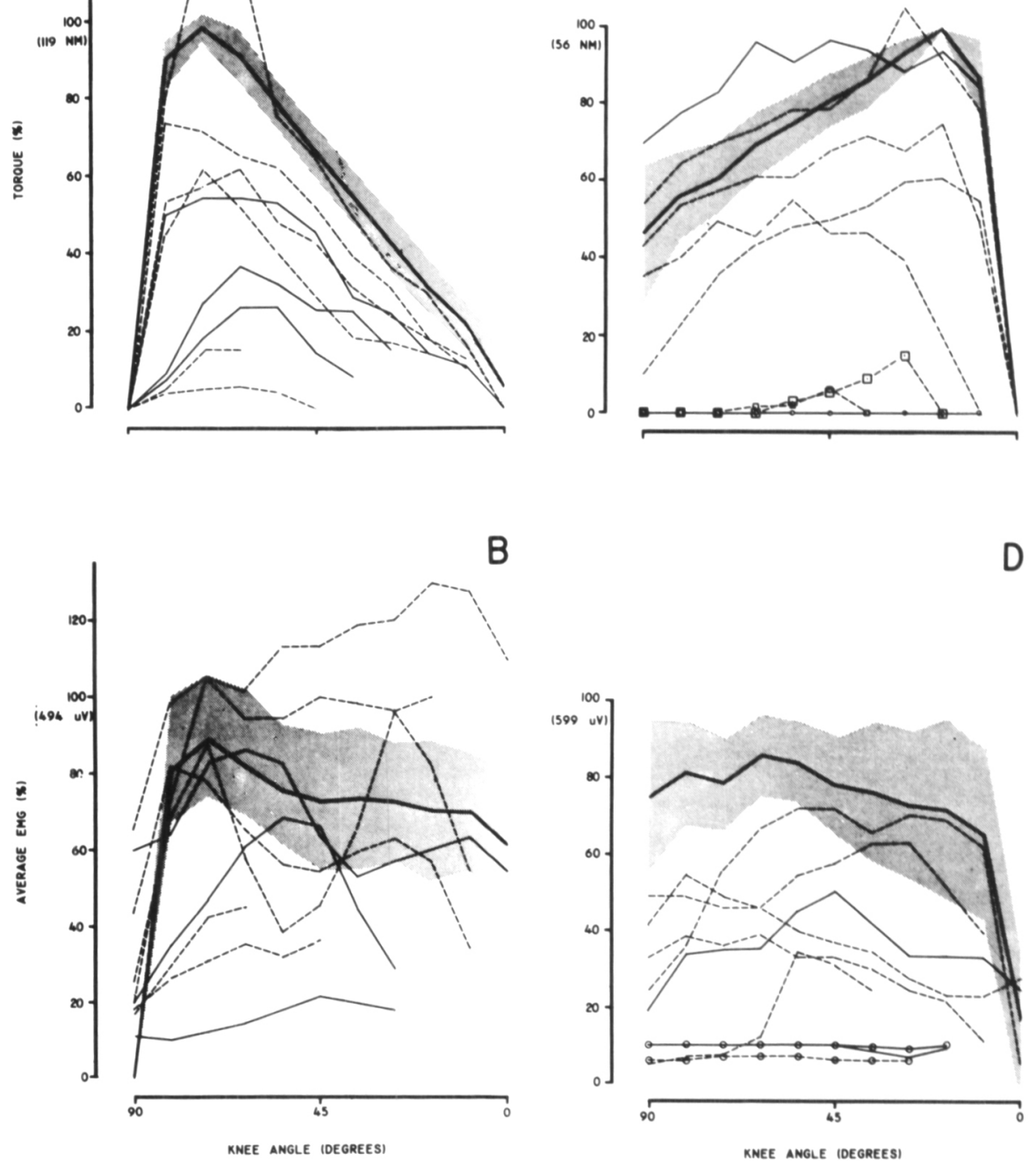

KNEE ANGLE IDEGREESI

Figure 5 - Comparison of torque-angle and EMG activity patterns during maximal voluntary isokinetic knee extension (A and $\mathrm{B}$ ) and flexion (C and D) movements at $30^{\circ} / \mathrm{s}$ in the group of 9 FA patients, 6 men (interrupted lines) and 3 women (thin, solid lines) with normal values. Knee angle is given on the $\mathrm{X}$-axis. In $\mathrm{A}$ and $\mathrm{C}$, torque in percent of maximum is given on the $\mathrm{Y}$-axis. Mean torque-angle curves (thick solid lines) are derived from 19 healthy women, and mean peak torque is given in brackets on $Y$ axis. In $B$ and $D$ average $E M G$ in percent of maximum is given on $Y$-axis. Mean values (thick solid lines) are derived from 17 healthy women and the mean normal peak activity given in brackets on the $\mathrm{Y}$-axis for vastus lateralis (B) and medial hamstrings (D). Shaded area indicates \pm ISD from the mean for torque in $A$ and $C$ and $E M G$ activity in $B$ and $D$.

Goslin and Charters, 1979; Richards, in press a) and older men and women (Larsson et al., 1979) have been described. In recent years the isokinetic dynamometer has become popular in the clinical setting for muscle strengthening exercises.

The use of the torque-angle curve as an index of dynamic strength in the knee extensor and flexor muscles has many advantages. The torqueangle curves give a profile of strength capacity throughout the movement, measure the effect of angular velocity on strength characteristics and provide a visual appreciation of reproducibility in the output of the voluntary effort. In neurological disorders, the 

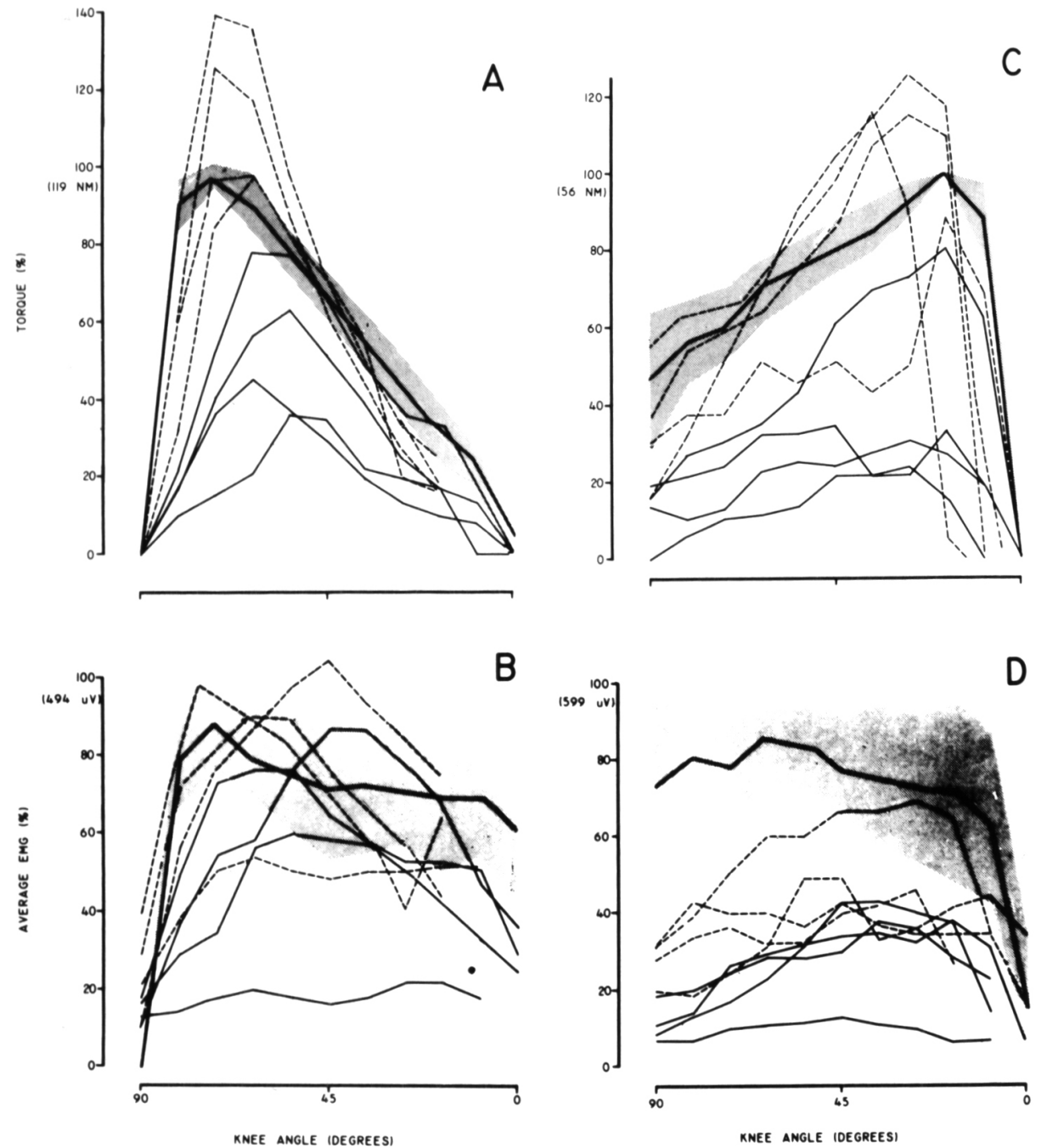

Figure 6 - Comparison of torque-angle and EMG activity patterns during maximal voluntary isokinetic knee extension (A and B) and flexion (C and D) movements at $30^{\circ} / \mathrm{s}$ in the group of 8 ARSACS patients, 4 men (interrupted lines) and 4 women (thin, solid lines) with normal values. Knee angle is given on the $\mathrm{X}$-axis. In $\mathrm{A}$ and $\mathrm{C}$, torque in percent of maximum is given on the $\mathrm{Y}$-axis. Mean torque-angle curves (thick solid lines) are derived from 19 healthy women, and mean peak torque is given in brackets on $Y$ axis. In $B$ and $D$ average EMG in percent of maximum is given on $Y$-axis. Mean values (thick solid lines) are derived from 17 healthy women and the mean normal peak activity given in brackets on the $\mathrm{Y}$-axis for vastus lateralis (B), and medial hamstrings (D). Shaded area indicates $\pm 1 S D$ from the mean for torque in $A$ and $C$ and EMG activity in $B$ and $D$.

torque-angle curve not only reflects the biomechanics of the strength production, but also the integration of neuromuscular control in producing the movement. Neuromuscular control mechanisms are implied in the ability of normal subjects to produce similar torque-angle records (reproducibility), to attain high torque values and to reach peak torque values early in the movement.
The angle of peak force production during the extension and flexion isometric contractions has been extensively studied since the days of Clarke et al., (1948). In maximal voluntary isometric contractions of the knee extensor muscles the peak force has been reported at $63^{\circ}$ of knee flexion (Williams and Stutzman, 1959) and between $50^{\circ}$ and $70^{\circ}$ in isokinetic contractions (Thorstensson, 1976; Knut- sson and Mårtensson, 1976). The torque-angle relationship during knee movements is the result of biomechanical (joint characteristics) and physiological (muscle control) interactions at the knee joint (Williams and Stutzman, 1959; Smidt, 1973). The tension a muscle can produce is known to vary with the length of the muscle (Ralston et al., 1947; Gordon et al., 1966). Movements of the knee joint alter the length-tension relationship in the muscles. The position of the hip joint also affects the length of the hamstring and rectus femoris muscles.

In the knee joint, the pathway followed by the instant center of rotation during knee extension and flexion movements changes the length of the moment arms of the quadriceps and hamstring muscles. According to Smidt (1973), the extension moment arm is longest $(4.9 \mathrm{~cm})$ in 30 to 45 degrees of knee flexion. The flexion moment arm is at maximum length $(4.1 \mathrm{~cm})$ in $45^{\circ}$ of knee flexion. Consequently, the extension torque produced at any point in the knee joint movement is a function of the length of the moment arm for the quadriceps muscle, muscle length, and other "neural factors" not directly related to muscle biomechanics.

The possibility of evaluating muscle strength at constant angular velocities in vivo with the isokinetic dynamometer has been used by other investigators to evaluate the force producing capacity in relation to muscle fiber composition. The capacity to produce high torque values at high angular velocities $\left(180^{\circ} / \mathrm{s}\right)$ has been positively correlated to the percent distribution of fast twitch (FT) fibers in the muscle (Thorstensson et al., 1976; Coyle and Costilli, 1979). In clinical practice, the isokinetic dynamometer can be applied to the evaluation of functional muscle capacity in different patients. The available evidence suggests that high torque capacity at $180^{\circ} / \mathrm{s}$ is dependent on the contribution of FT fibers. At a relatively slow angular velocity $\left(30^{\circ} / \mathrm{s}\right)$ both the FT and slow twitch (ST) fibers can be expected to contribute to the strength output (Fugl-Meyer et al., 1979).

Knutsson and Mårtensson (1976) have used the isokinetic torque-angle relationship throughout the knee move- 
ment at different angular velocities as an index of functional muscle control in patients with spastic pareses. In this study isokinetic torque-angle curves were applied to the description of dynamic muscle strength in two groups of ataxic patients. Dynamic strength during knee extension and flexion was generally decreased in the majority of the patients.

In comparison to normal values, deviations were observed in the amplitude, shape and reproducibility of the torque-angle curves of the FA patients. A lower strength profile was demonstrated in the older, wheelchairbound patients with a marked decrease in the amplitude of the torque (muscle weakness) and range of knee movement. In some FA patients, the decrease in torque producing capacity was even more marked for flexion movements at $30^{\circ} / \mathrm{s}$. The lack of reproducibility in repeated isokinetic movements suggests a lack in constancy in motor output for the same task. Such torque-angle measurements have been shown to be reproducible in healthy subjects (Knuttson and Martensson, 1976; Richards, in press a).

The torque-producing capacity in the ARSACS patients differed in several respects from that in the FA patients. The ARSACS patients generally were able to produce torque throughout a greater range of knee movement and the torque-angle curves at $30^{\circ} / \mathrm{s}$ were more reproducible (visual assessment). All the ARSACS patients were able to produce torque during knee extension and seven during flexion movements at $180^{\circ} / \mathrm{s}$ (the lowest torque at the $45^{\circ}$ knee position was $14 \mathrm{Nm}$ and the highest 78 $\mathrm{Nm}$ in comparison to $73.5 \pm 3.1 \mathrm{Nm}$ (mean, \pm ISE, $N=19$ ) in healthy women. In the FA patients, two could not produce measurable torque during knee extension movements and four for flexion movements at $180^{\circ} / \mathrm{s}$. In contrast to the FA patients, the decreased muscle strength did not appear to be directly related to the evolution of the disease process.

Differences in the torque-producing capacity in the FA and ARSACS patients may in part be related to the stability of the trunk. Although all the patients were seated and immobilized
A

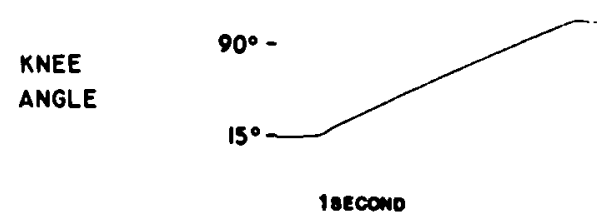

TORQUE
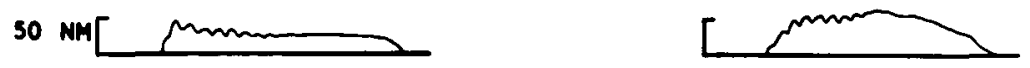

VM

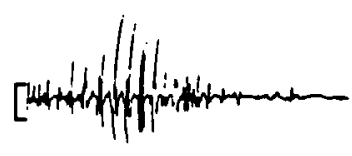

VL
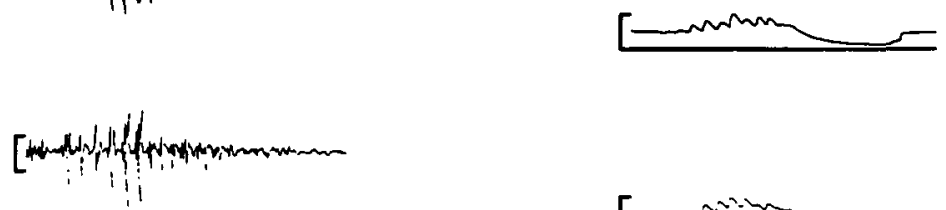

MH

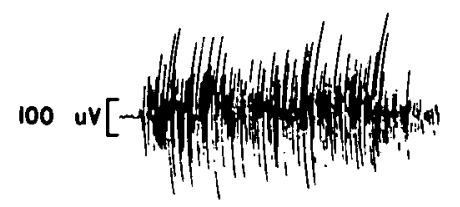

Figure 7 - Polygraph recordings during isokinetic knee flexion movements at $30^{\circ}$ in a patient (CG) with ARSACS. In A and B tracings give from above: knee angle, torque, and $E M G$ activity in vastus medialis (VM), vastus lateralis (VL) and medial hamstrings $(\mathrm{MH})$. Raw EMG activity given in A and integrated EMG with a time constant of $0.2 \mathrm{~s}$ in B. Calibration bars indicate $50 \mathrm{Nm}$ for torque records and $100 \mathrm{uV}$ for EMG records.

in a similar manner, the kyphoscoliosis and truncal ataxia present in most of the FA patients imposed variations in the trunk position. It is likely that the more stable trunk position in the ARSACS patients contributed to the production of knee extensor and flexor torque (Mendler, 1967). Several other neuro-muscular mechanisms such as: corticospinal tract degeneration, loss of proprioception, motor axonopathy, and muscle volume reduction are most likely implicated in the dynamic muscle strength in these ataxic patients.

\section{Electromyograms During} Isokinetic Knee Movements

Activation patterns (EMG) in the muscles producing a movement or force give some insight into mechanisms of neuro-muscular control which are implicated in the muscle contractions. The method of EMG analysis used in the present study, has been reported for the evaluation of electromyograms in leg muscles during gait (Knutsson and Richards, 1979) and has recently been applied to the description of EMG profiles during isokinetic knee movements (Richards, 1980). In the present study, the EMG activity in the vastus lateralis (VL) and medial hamstrings $(\mathrm{MH})$ muscles was chosen to represent the extensor and flexor muscle groups acting at the knee joint during isokinetic movements.

The amplitude of the EMG activity in the majority of both the FA and ARSACS patients was reduced rela- 
tive to the mean peak normal amplitude in $\mathrm{MH}$ during knee flexion at $30^{\circ} / \mathrm{s}$. Such a reduced amplitude level suggests alterations in motor unit recruitment in these patients. Although caution must be exerted in comparing amplitude levels among different subjects in surface EMG, the fact that a reduced EMG amplitude was not a consistent finding in the VL during knee extension movements favors a physiological explanation for the activity levels. Using a similar EMG analysis technique, a reduced capacity to activate motor units during gait movements has been described in hemiplegic patients (Knutsson and Richards, 1979).

Several findings from EMG studies with intramuscular electrodes may be pertinent to the understanding of the reduced integrated EMG activity observed in these ataxic patients. EMG studies have described subtle signs of denervation such as: rare fibrillations at rest, increased number of polyphasic action potentials of low amplitude, and a reduced recruitment pattern in FA (Dyck and Lambert, 1968; Peyronnard et al., 1976; Bouchard et al., 1979b). On the other hand, the EMG in ARSACS patients suggests a mixed pattern of myelopathic and neuropathic features with: fasciculations, frequent fibrillations, and more polyphasic motor unit potentials of high or low amplitude. In these patients the recruitment is reduced in proximal muscles and even more affected in distal muscles in which signs of complete denervation were sometimes found (Bouchard et al., 1979b). Furthermore, the motor nerve conduction velocities have been shown to be much lower than normal in ARSACS patients and to fall within the lower range of normal limits in FA patients (Bouchard et al., 1979b).

The shape and amplitude of the EMG activity curve, which gives an indication of motor unit recruitment patterns during the movement were variable in comparison to normal among the FA patients in VL during knee extension at $30^{\circ} / \mathrm{s}$. In patients with spasticity, different types of abnormal muscle activation may occur. Factors which may contribute to these abnormalities include: hyperactive stretch reflexes, decreased muscle activation and pathological co-activation of antagonistic muscles. These factors may contribute to a varying degree in the motor dysfunction in the individual patient (Knutsson and Richards, 1979).

Clinically, stretch reflexes are assessed by testing the strength of a reflex muscular contraction during passive movement of a limb. However, in functional movements, stretch is imposed on muscles by joint movements to muscular contractions and interactions with external forces. These movements implicate the interaction of agonistic, synergistic and antagonistic muscles controlled by a central processing system. McLennan (1977) emphasized the need to evaluate antagonistic muscle activation during both active and passive movements in spastic patients. In order to estimate the degree of antagonistic activation during isokinetic movements, a coactivation index, modified from that described by McLennan (1977) was used in the present study. The calculation of a co-activation index by comparing the activation in the same muscle within the same subjects during active shortening and lengthening obviated the problem of comparing EMG amplitudes in different subjects.

Although FA patients present clinical signs of spasticity (Tyrer, 1975; Geoffroy et al., 1976; Bouchard et al., 1979a), a greater co-activation of antagonists was expected in the ARSACS patients in whom spasticity is a cardinal sign (Bouchard et al., 1978). In the FA patients, high co-activation indexes were present in the VL and MH of the more severely affected patients confined to a wheelchair, and to a lesser degree in the $\mathrm{MH}$ of the younger, ambulatory patients. The increased co-activation seen in the more affected patients suggests an alteration in the agonist-antagonist interaction with progression of the disease.

In the ARSACS patients, a higher than normal co-activation index was found in five patients in the $\mathrm{MH}$ during extension movements and in three patients in VL during flexion movements at $30^{\circ} / \mathrm{s}$. Two of these patients demonstrated increased coactivation indexes in both VL and $\mathrm{MH}$, and in two of the eight patients clonic discharges were elicited in the VL during flexion movements. It is interesting to note that an increased co-activation index was more frequent in the MH than the VL in the ARSACS patients. In spastic patients, McLennan (1977) also reported an increased co-contraction index in both the quadriceps and hamstring muscles, while Sahrman et al. (1974) described greater spasticity in knee flexor muscles as determined from the EMG elicited by passive movements. It should be noted that continuous EMG activity and the low amplitude of agonistic EMG activity in some patients contributed to the calculation of high co-activation indexes in these patients since the index was a ratio of antagonistic/agonistic EMG amplitude.

The results have demonstrated the application of a standardized method of evaluation to the description of dynamic muscle function in two groups of patients. The findings in this preliminary study are applicable only to the limited number of patients evaluated. These data will provide comparative information for the evaluation of the effects of therapy on dynamic muscle function in the individual patients.

\section{ACKNOWLEDGEMENTS}

This study was supported by a grant from l'Association Canadienne de l'Ataxie de Friedreich.

\section{REFERENCES}

ANDERMANN, F. (1976) Nicolaus Friedreich and degenerative atrophy of the posterior columns of the spinal cord. Can. J. Neurol. Sci., 3, 275-277.

BARBEAU, A. (1978) Emerging treatments: Replacement therapy with choline or lecithin in neurological diseases. Can. J. Neurol. Sci., $5,157-160$.

BELL, J.M. and CARMICHAEL, E.A. (1939) On hereditary ataxia and spastic paraplegia. In: Treasury of Human Inheritance, Vol. 4, Cambridge Press, London, pp. 141-284.

BOUCHARD, J.P., BARBEAU, A., BOUCHARD, R. and BOUCHARD, R.W. (1978) Autosomal recessive spastic ataxia of Charlevoix-Saguenay. Can. J. Neurol. Sci., 5, 61-70.

BOUCHARD, J.P., BARBEAU, A., BOUCHARD, R., PAQUET, $M$. and BOUCHARD, R.W. (1979a) A cluster of Friedreich's ataxia in Rimouski, Québec. Can. J. Neurol. Sci., 6, 205-208. 
BOUCHARD, J.P., BARBEAU, A., BOUCHARD, R. and BOUCHARD, R.W. (1979b) Electromyography and nerve conduction studies in Friedreich's ataxia and autosomal recessive spastic ataxia of Charlevoix-Saguenay (ARSACS). Can. J. Neurol. Sci., 6, 185-189.

BROWN, J.R. (1962) Diseases of the Cerebellum. In: Clinical Neurology, Vol. 3 (Baker, Ed.), pp. 1406-1455.

CAMPBELL, D.E. and GLENN, W. (1979) Foot-pounds of torque of the normal knee and the rehabilitated post-meniscectomy knee. Phys. Ther., 59, 418-421.

CLARKE, H.H. (1948) Objective strength tests of affected muscle groups involved in orthopedic disabilities. Res. Quart., 19, 118-147.

COYLE, E.F., COSTILL, D.L. and LESMES, G.R. (1979) Leg extension-power and muscle fiber composition. Med. Sci. Sports, I1, 12-15.

DYCK, P.J. and LAMBERT, E.H. (1968). Lower motor and primary sensory neuron diseases with peroneal muscular atrophy. I. Neurologic, genetic and electrophysiologic findings in various neuronal degenerations. Arch. Neurol., 18, 603-625.

FUGL-MEYER, A.R., NORDIN, G., SJÖSTROM, M. and WÄHLBY, L. (1979) Achilles tendon injury. Scand. J. Rehabil. Med., 11, 37-44.

GEOFFROY, G., BARBEAU, A., BRETON, G., LEMIEUX, B., AUBE, M., LEGGER, C. and BOUCHARD, J.P. (1976) Clinical description and roentgenologic evaluation of patients with Friedreich's ataxia. Can. J. Neurol. Sci., 3, 279-286.

GORDON, A.M., HUXLEY, A.F. and JULIAN, F.J. (1966) The variation in isometric tension with sarcomere length in vertebrate muscle fibres. J. Physiol. (London), 184, 170-192.

GOSLIN, B.R. and CHARTERS, J. (1979) Isokinetic dynamometry: normative data for clinical use in lower extremity (knee) cases. Scand. J. Rehabil. Med., 11, 105-109.

GRINKER, R.R. and SAHS, A.L. (1966) Neurology, 6th ed., Charles C. Thomas, Springfield, 11l., pp. 686-689.
HISLOP, H. and PERRINE, J.J. (1967) The isokinetic concept of exercise. Phys. Ther., 47, 114-117.

KNUTSSON, E. and MÅRTENSSON, A. (1976) Action of dantrolene sodium in spasticity with low dependance on fusimotor drive. J. Neurol. Sci., 29, 195-212.

KNUTSSON, E. and RICHARDS, C. (1979) Different types of disturbed motor control in gait of hemiparetic patients. Brain, 102, 405430.

LARSSON, L., GRIMBY, G. and KARLSSON, J. (1979) Muscle strength and speed of movement in relation to age and muscle morphology. J. Appl. Physiol., 46, 451-456.

MCLENNAN, D.L. (1977) Co-contraction and stretch reflexes in spasticity during treatment with baclofen. J. Neurol. Neurosurg. Psychiatry, 40, 30-38.

MENDLER, H.M. (1967) Effect of stabilization on maximum isometric knee extensor force. Phys. Ther. 47, 375-379.

MOFFROID, M., WHIPPLE, R., HOFKOSH, J., LOWMAN, E. and THISTLE, H. (1969) A study of isokinetic exercise. Phys. Ther., 49, 735-747.

NICHOLAS, J.A., STRIZAK, A.M. and VERRAS, G. (1976) A study of thigh muscle weakness in different pathological states of the lower extremity. Am. J. Sports Med. 4, 241-248.

PEYRONNARD, J.M., BOUCHARD, J.P., LAPOINTE, L., LAMONTAGNE, A., LEMIEUX, B. and BARBEAU, A. (1976) Nerve conduction studies and electromyography in Friedreich's ataxia. Can. J. Neurol. Sci., 4, 313-317.

PEYRONNARD, J.M., CHARRON, L. and BARBEAU, A. (1979) The neuropathy of Charlevoix-Saguenay ataxia: an electrophysiological and pathological study. Can. J. Neurol. Sci., 6, 205-208.

PRATT, R.T.C. (1967) The Genetics of Neurological Disorders, (Roberts, Ed.), Oxford University Press, London, pp. 33-38.

RALSTON, H.J. and INMAN, V.T. (1947) Mechanics of human isolated voluntary muscle. Amer. J. Physiol., 151, 612-620.
RICHARDS, C. (1980) Dynamic muscle function in human normal, pathological and prosthetic knee joints. Ph.D. thesis, McGill University.

RICHARDS, C. (in press a) Dynamic strength characteristics during isokinetic knee movements in healthy women. Physiother. Can.

RICHARDS, C. (in press b) Knee extensor and flexor muscle activation patterns during isokinetic movements in healthy women. Physiother. Can.

SAHRMANN, S.A., NORTON, B.J., BOMZE, H.A. and ELIASSON, S.G. (1974). Influence of the site of the lesion and muscle length on spasticity in man. Phys. Ther. 54, 1290-1297.

SMIDT, G.L. (1973) Biochemical analysis of knee flexion and extension. J. Biomech., 6 , 79-92.

SPILLER, W.G. (1910) Friedreich's Ataxia. J. Nerv. Ment. Dis., 37, 411-435.

THISTLE, H., HISLOP, H., MOFFROID, M. and LOWMAN, E.W. (I967) lsokinetic contraction: a new concept of resistance exercise. Arch. Phys. Med. Rehabil., 48, 279282.

THORSTENSSON, A. (1976) Muscle strength, fibre types and enzyme activities in man. Acta Physiol. Scand., Suppl. 443.

THORSTENSSON, A., GRIMBY, G. and KARLSSON, J. (1976) Force-velocity relations and fiber composition in human knee extensor muscles. J. Appl. Physiol., 40, 1216.

TYRER, J.H. (1975) Friedreich's ataxia. In: Handbook of Neurology, Vol. 21 (Vinken and Bruyn, Eds.), pp. 319-364.

TYRER, J.H. and SUTHERLAND, J.M. (1961) The primary spinocerebellar atrophies and their associated defects, with a study of the foot deformity. Brain, 84, 289300.

WILLIAMS, M. and STUTZMAN, L. (1959) Strength variation through the range of joint notion. Phys. Ther., 39, 145-152.

WILSON, S.A.K. (1954) Friedreich's disease. In: Handbook of Neurology, Vol. 2 (Bruce, Ed.), pp. 1078-1091. 